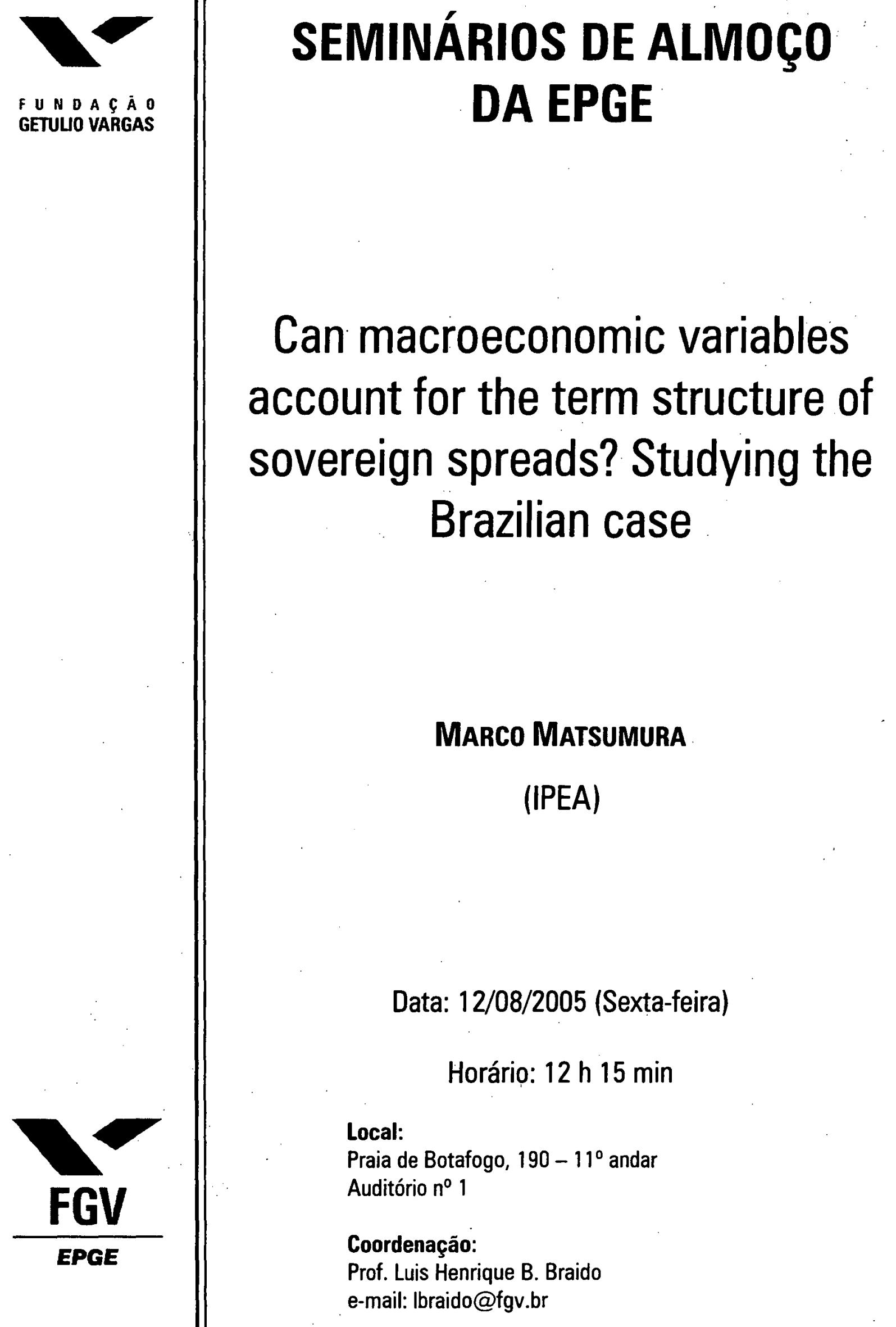




\section{Can Macroeconomic Variables Account for the Term Structure of Sovereign Spreads? Studying the Brazilian Case}

Marco Matsumura 1 ,

Ajax Moreira2

June 2005

\section{Introduction}

This article develops a model combining term structure and vector autoregressive models to analyze sovereign and domestic term structure of interest rates. The model is based upon the articles by Ang and Piazzesi (2003) and Ang, Dong and Piazzesi (2005). One distinctive feature brought by those articles was to allow the possibility of incorporating macroeconomic variables as state variables alongside the latent state variables of the traditional term structure models. The joint behavior of the yield curve and macroeconomic variables permits the study of public policy effects on the yield curve and vice-versa. Diebold, Piazzesi and Rudebusch (2005) argues that, "From a macroeconomic perspective, the short-term interest rate is a policy instrument under the direct control of the central bank, which adjusts the rate to achieve its economic stabilization goals. From a finance perspective, the short rate is a fundamental building block for yields of other maturities, which are just risk-adjusted averages of expected future short rates."

The idea of Ang and Piazzesi's work is to use a discrete time specification of an Affine term structure model (see Duffie and Kan 1996 for instance) which is at the same time a Vector Autoregressive (VAR) model. Then, this model can be extended with the addition of macroeconomic variables as in the Macro VAR literature, without loosing the affine characterization. Also, the no-arbitrage

\footnotetext{
Dimac/IPEA: marcom@ipea.gov.br

2 DIMAC/IPEA : ájax@ipea.gov.br
} 
condition is present in the model, a restriction not necessarily enforced in Macro VAR models. Finally, all the flexibility and advantages of the VAR model are retained. Variance decompositions and impulse response functions can be easily calculated.

Thus, this line of research can take advantage of using the tools and results of Macro VAR studies and Affine term structure models one into the other to investigate questions of interest in both public policy and asset pricing.

Our article extends the work by Ang and Piazzesi in a number of ways. First, we propose a simplified specification and a method of estimation. This was motivated by the recognition after various experimentations with both Maximum Likelihood and Monte Carlo Markov Chain that the estimation process turns out to be very delicate and difficult, which is caused by the high dimensionality and high nonlinearity of the model.

This proposal is a multidimensional affine model for the yield curve that is as easy to estimate as usual empirical procedures. However, we must say that this simplification had the effect of reducing the possibility of discussing monetary policy questions, and so we concentrate only on the relation between macroeconomic variables and the term structure of interest rates and of credit spreads.

Second, we developed an extended model incorporating the possibility of default and a credit spread variable. This is a version of Duffie and Singleton' $s$ (1997) reduced model. Here a question of central interest is trying to understand how the sovereign spread due to default is related to macroeconomic variables (and to monetary policy in the general model).

The third contribution was to present and compare several results for different specifications of the model for US Treasury, swaps from BM\&F (Brazilian Future Markets Exchange), and emerging market sovereign bonds. We remark that the simplification of the estimation process allowed the addition of the short spread in a 
model that would otherwise have a too high dimension. And credit risk is a fundamental variable concerning all emerging countries.

To the authors' knowledge, in the existing models in the credit risk literature, the spread only reacts to the default free reference short-term interest rate. For example, Duffie, Pedersen and Singleton (2002) study the dynamics of the Russian term structure of interest rates. They calculate the model implied instantaneous spreads due to credit risk and compute via an impulse response function how it relates to the Government reserves or to the price of the petroleum. However, in their model, macroeconomic variables play no direct role in the determination of the spread dynamics.

Thus, the present study focuses on measuring the effects of macroeconomic shocks over the term structure of interest rates and of credit spreads. Ang and Dong and Piazzesi (2005) take full account of the monetary issues, using MCMC. We also tried to used MCMC besides Maximum likelihood and intend to tackle this problem in future work.

In the following, we present the AP' $s$ general framework and after that we show the specific choices where we ran the estimations.

\section{Affine Term Structure Model with Macro Factors}

\subsection{Initial comments}

In AP' $s$ approach, the economy is represented through the state variables $X$ that have observable macro components $m$ and monetary or financial components $u$. The dynamics of $X$ is described by a VAR, and the monetary policy by the relation between the short rate $r$ and the state variables of the economy. A key idea in $A P^{\prime} s$ article is to make that relation a combination of the Taylor' $s$ rule $r_{t}=a_{0}+$ $a_{1} f_{t}+v_{t}$, where $t_{t}$ is a vector of observable macro factors and $v_{t}$ represents components not explained by macro factors, and of the affine term structure equation $\mathrm{r}_{\mathrm{t}}=\mathrm{b}_{0}+\mathrm{b}_{1} X_{\mathrm{u}_{\mathrm{t}}}$, where $X_{4}$ is a vector of latent factors, that is, $r_{t}=d_{0}+d_{11}$ $X o_{t}+d_{12} X u_{t}$. 
Then, the model will be affine: the relation between the interest rates of chosen maturities $Y$ arid the state variables is linear given the parameters. So $Y$ and $X$ have the same dynamic properties from the time series point of view. The dynamics of $X$ is given a priori, and its parameters are found using a historical series of $Y$. Change of variables is used to obtain $Y^{\prime} s$ distribution in terms of $X^{\prime} \mathrm{s}$.

Our proposal departs from AP's when we consider that the short rate describes the state of the economy and hence is a state variable, and when we represent the monetary policy in the usual form in the VAR literature, identifying the contemporary relations between the state variables. Then, we do not need to invert the function from $X$ to $Y$ to make the estimation of all parameters at once.

With those modifications, one looses the possibility of describing some aspects of the monetary condition that would exist in a model with more unobservable latent monetary factors. On the other hand, this model is much easier to be estimated. And as we will see later on, even with our assumptions, the estimation of the risk premium will be far from being a straightforward task.

In our approach, we directly estimate the short rate first to fix some of the parameters. This is possible because we have set $d_{b}=0$ and $d_{1}=(1,0, \ldots, 0)$ and included $r_{t}$ as one of the state variables.

\subsection{State variables}

The state variables will have the following dynamics:

$X_{t}=\mu+\phi X_{t-1}+V \varepsilon_{t}$

The financial factors $i_{t}$ and $s_{t}$ and the macro variables $m_{t}$ of the vector $X_{t}$ are $A R(1)$ factors, but the macro factors can include lagged factors of any order.

\subsection{The Pricing Kernel}

Bonds in our economy will be priced using the Martingale approach of Harrison and Kreps (1979). Assuming no arbitrage, we know that the existence of an 
equivalent martingale measure $Q$ is guaranteed. The price at time $t$ of an asset that pays no dividend is

$V_{t}=E_{t}^{Q}\left[\exp \left(-r_{t}\right) V_{t+1}\right]$

Denoting by $\xi_{t}$ the Radon-Nikodym derivative

$\frac{d Q}{d P}=\xi r$

it can be show that $E_{t}^{Q}\left(Z_{\mathrm{t}+1}\right)=\mathrm{E}_{\mathrm{t}}\left(\xi_{\mathrm{t}+1} Z_{\mathrm{t}+1}\right) / \xi_{\mathrm{t}}$

Using a discrete time analogy of the Girsanov's theorem, we assume that $\xi_{t}$ follows the process $\xi_{t+1}=\xi_{t} \exp \left(-0.5 \lambda_{t}^{*} \lambda_{t}-\lambda_{t} \varepsilon_{t+1}\right)$, where $\lambda_{t}$ represents time-varying market prices of risk associated with the sources of uncertainty $\varepsilon_{t}$. We follow the literature specifying the market prices of risk as an affine process: $\lambda_{t}=\lambda_{0}+\lambda_{1} X_{t}$.

The pricing kernel is defined as $m_{t}=\exp \left(-r_{t}\right) \xi_{t+1} / \xi_{t}$.

\subsection{Pricing of bonds}

Using the pricing kernel, the price of a $(n+1)$-period bond will be: $p_{t}^{n+1}=\mathrm{E}_{\mathrm{t}}\left(\mathrm{m}_{\mathrm{t}+1} p_{t+1}^{n}\right)$

Choosing $r_{\mathrm{t}}=\delta_{0}+\delta_{1} \mathrm{X}_{\mathrm{t}}$, the price of the bond will be Affine: $p_{t}^{n}=\exp \left(\bar{A}_{n}+\bar{B}_{n} \mathrm{X}_{\mathrm{t}}\right)$

Then, it can be shown that the coefficients $\bar{A}_{n}$ and $\bar{B}_{n}$ can be calculated recursively through the following relations:

$$
\begin{aligned}
& \bar{A}_{1}=\delta_{0} \\
& \bar{B}_{1}=\delta_{1} \\
& \bar{A}_{n+1}=-\delta_{0}+\bar{A}_{n}+\left(\mu^{\prime}-\lambda_{0}^{\prime} V\right) \bar{B}_{n}+0.5 \bar{B}_{n}^{\prime} \vee \vee \bar{B}_{n} \\
& \bar{B}_{n+1}=-\delta_{1}+\left(\phi^{\prime}-\lambda_{1}^{\prime} V\right) \bar{B}_{n}
\end{aligned}
$$

The n-period Yield is:

$$
\begin{aligned}
& Y_{n}^{t}=-\log p_{t}^{n} / \mathrm{n}=\mathrm{A}_{\mathrm{n}}+\mathrm{B}_{\mathrm{n}} \mathrm{X}_{\mathrm{t}} \\
& \mathrm{A}_{\mathrm{n}}=\bar{A}_{n} / \mathrm{n} \\
& \mathrm{B}_{\mathrm{n}}=\bar{B}_{n} / \mathrm{n}
\end{aligned}
$$


or

$$
Y_{t}=\left[\begin{array}{c}
Y_{t}^{\prime} \\
\cdot \\
Y_{t}^{n}
\end{array}\right]=\left[\begin{array}{c}
A^{\prime} \\
\cdot \\
A^{n}
\end{array}\right]+\left[\begin{array}{c}
B^{1} \\
\cdot \\
B^{n}
\end{array}\right] X_{t}=\mathrm{A}+\mathrm{B} \mathrm{X}_{t}
$$

\subsection{Introducing the Spread}

An important component in the term structure of emerging countries is the spread due to the possibility of default of the bond. In the literature, two lines of research have developed regarding this question: the structural and the reduced models. We choose to implement a discrete version of the reduced model as presented in Duffie-Singletorı (1999):

- Let $h_{s}$ be the conditional probability at time $s$ under a risk neutral probability $Q$ of default between $s$ and $s+1$ given the information available at time $s$ in the event of no default by s.

- Let $\phi_{\mathrm{s}}$ be the recovery upon default.

- Let $V_{t}$ denote the price of a defaultable claim.

Then:

$V_{t}=h_{t} e^{-r t} E_{t}^{Q}\left[\phi_{t+1}\right]+\left(1-h_{t}\right) e^{-r t} E_{t}^{Q}\left[V_{t+1}\right]$

Using the Recovery of Market Value hypothesis $E_{s}^{Q}\left(\phi_{s+1}\right)=\left(1-L_{s}\right) E_{s}^{Q}\left(V_{s+1}\right)$, where $L_{s}$ denotes the loss rate upon default, it follows that:

$V_{t}=\left(1-h_{t}\right) e^{-r t} E_{t}^{Q}\left(V_{t+1}\right)+h_{t} e^{-r t}\left(1-L_{t}\right) E_{t}^{Q}\left(V_{t+1}\right)$

Or,

$V_{t}=E_{t}^{Q}\left(V_{t+1}\right)\left(\left(1-h_{t}\right) e^{-r t}+h_{t} e^{-r t}\left(1-L_{t}\right)\right)=E_{t}^{Q}\left(V_{t+1}\right) e^{-r t}\left(1-h_{t} L_{t}\right)$

Now, note that $\exp \left(h_{t} L_{t}\right) \approx 1-h_{t} L_{t}$. If we set that relation to be an equality just redefine $L_{t}$ ), we will have

$V_{t}=E_{t}^{Q}\left(V_{t+1}\right) \exp \left(-r_{t}+h_{t} L_{t}\right)$

as in the continuous case. 
Thus, the affine setting can be maintained. We call the additional term $s_{t}=h_{t} L_{t}$ the spread due to default. The spread $s$ will be another state variable.

If we denote by $o_{2}^{n}$ the price of a defaultable bond, then using the equivalent martingale measure, we have that

$p_{t}^{n+1}=E_{\imath}^{Q}\left[\exp \left(-r_{t}-s_{t}\right) p_{t+1}^{n}\right]$

Moreover, the pricing kernel and the pricing equation can be found using equations that bear resemblance to the previous ones.

\subsection{Likelihood}

The likelihood is the density function of the joint distribution of $\left(X_{t}, Y_{t}\right)$. To calculate it, we will invert those variables in terms of $\left(X_{t}, u_{t}\right)$, that is:

$$
\left[\begin{array}{l}
X_{t} \\
u_{t}
\end{array}\right]=\left[\begin{array}{cc}
I & 0 \\
-B & I
\end{array}\right]\left[\begin{array}{l}
X_{t} \\
Y_{t}
\end{array}\right]-\left[\begin{array}{l}
0 \\
A
\end{array}\right],
$$

We considered the risk free short rate $r_{t}$ as measured without errors, and that other yields have an i.i.d. measurement error $u_{t}$.

Chen and Scott (1993) first introduced the idea of adding measurement errors in some yields. The number of yields measured without error is the same as the number of latent state variables. Then, each additional yield has to come with a measurement error $u_{t}$ to make them compatible with the previous yields. The error $u_{t}$ is independent of all other variables.

Using $\left(^{*}\right)$ and the know distribution of $\left(X_{t}, u\right)$, applying change of variable formula we have:

$$
\begin{aligned}
& \mathrm{L}(\psi)=\mathrm{f}_{\mathrm{X}}(\mu, \phi, \mathrm{V})+\mathrm{f}_{\mathrm{u}}\left(\mu, \phi, \mathrm{V}_{,} \lambda_{0}, \lambda_{1}\right)+\mathrm{f}_{0} \\
& f_{x}\left(X_{t} \mid X_{t-1}\right)=.5\left\{(\mathrm{~T}-1) \log \left(\operatorname{det}\left(\mathrm{W}^{\prime}\right)\right)+\sum_{t=2}^{T}\left(X_{t}-\mu-\phi X_{t-1}\right)^{\prime}\left(V V^{\prime-1}\right)\left(X_{t}-\mu-\phi X_{t-1}\right)\right\} \\
& f_{u}\left(u_{t}^{n}\right)=-0.5\left\{(\mathrm{~T}-1) \sum_{i=1}^{K} \sigma_{i}^{2}+\sum_{t=2}^{T} \sum_{i=1}^{K} \frac{\left(u_{t}^{i}\right)^{2}}{\sigma_{i}^{2}}\right\} \\
& \mathrm{f}_{0}=(\mathrm{T}-1) \log (\operatorname{det}(\mathrm{J})), \quad \mathrm{J}=\left[\begin{array}{cc}
I_{p} & 0 \\
-B & I_{n}
\end{array}\right],
\end{aligned}
$$




\subsection{Estimation}

The log likelihood is the sum of 3 terms, $f_{x}(\mu, \phi, V), f_{u}\left(\mu, \phi, V, \lambda_{0}, \lambda_{1}, \sigma\right), f_{0}$, where:

1) $f_{0}=0$ for $\operatorname{det}(J)=1$

2) The functions $A(),. B($.$) can be reparameterized with no loss of generality making$ $\lambda_{0}^{*}=\mu^{\prime}-\lambda_{0}^{\prime} V, \lambda_{1}^{*}=\phi^{\prime}-\lambda_{1}^{\prime} V$, and $\lambda^{*}=\lambda_{0}^{*}, \lambda_{1}^{*}$, so

$u_{t}=Y_{t}-A\left(\mu, \phi, V, \lambda_{0}, \lambda_{1}\right)-B\left(\phi, V, \lambda_{1}\right) X_{t}=Y_{t}-A\left(V, \lambda^{\star}\right)-B\left(\lambda^{*}\right) X_{t}$

3) In the function $f_{u}($.$) the parameters \sigma_{i}$ can be substituted by its maximum likelihood estimator

$$
\sigma_{i}^{2}\left(V, \lambda^{*}\right)=\sum_{i=1}^{K} \frac{\left(Y_{i}^{i}-A\left(V, \lambda^{*}\right)-B\left(\lambda^{*}\right)\right)^{2}}{T}
$$

4) Thus $f_{u}\left(\mu, \phi, V^{\prime}, \lambda_{0}, \lambda_{1}, \sigma\right)$ can be reparameterized with no loss as $f_{u}\left(\lambda^{*}, V\right)$.

Considering items $1-4, L(\psi)=f_{x}(\mu, \phi, V)+f_{u}\left(\lambda^{*}, V\right)$.

The maximization problem was solved in a conditional way making

$\max _{\psi} L(\psi)=\max _{\mu, \phi} f_{x}(\mu, \phi, V)+\max f_{u}\left(\lambda^{*} \mid V\right)$

The first problem, maximizing $f_{x}$, corresponds to the estimation of the VAR model, and the second one to a non-linear maximization in the vector $\lambda^{\star}$.

Moreover, using simulated data we concluded that the use of conditional maximization caused negligible alteration in the likelihood.

In this way, we greatly simplified the estimation process, reducing the dimension of the maximization. So, one state variable is always the short rate, considered measured without error. Macro and spread factors can be added depending on the specification.

We remark that the longer rates (considered as measured with errors) are needed to identify the constant risk premium and the constant term. It can be show that an estimation using only the state variable cannot distinguish the long-term mean short rate from the risk premium. 
The use of an observable short rate is not a relevant restriction since in the affine model, yields of longer maturities are linear functions $Y=B X+A$ of the state variable. Since the characteristic roots of the dynamics of $Y$ and $X$ are the same, only differences of scale distinguishes both processes and the estimation should not be significantly different.

Also, we remark that the effect of each risk premium over the likelihood is different. Thus, one may be easier to estimate than the other.

\section{Using the Model}

\subsection{Initial comments}

To show the flexibility of this model and the difficulties of the estimation of the risk premiums, we considered 4 specifications. The first, model $(A)$, is a model that uses swap rates with various maturities from BM\&F (Brazilian futures exchange) to study the Brazilian market. The second, Model $(B)$ is an extension of the previous one that includes a macro variable - the log of the Brazilian Real R\$/US\$ exchange rate - to analyze the interaction between nominal exchange rate shocks and interest rates. The third, model (C), is similar to the first model, but is estimated using constant maturity interest rates of the American market calculated by the FED. Finally, the fourth model (D) relates the term structure of the Brazilian sovereign spread with the American interest rates and with a measure of vulnerability of the debt of the Brazilian economy.

The 4 specifications utilize 2 sets of data. The first one, utilized by $(A)$ and $(B)$, contain the 1 day swap e swaps of selected maturities - 1, 2, 3, 6, 9, 12, 18, 24 and 36 months - produced by the BM\&F, covering the period from 01/01/2001 to $30 / 05 / 2005$ and containing 1035 daily observations. The second set, utilized by the other specifications, contain: 1) constant maturity interest rates calculated by FED of maturities of 1 month and $\{1,5,10,20\}$ years; 2) Brazilian sovereign spread rates of maturities of $\{1,5,6,10,20\}$ years calculated by the authors using bonds 
form Republic of Brazil; and 3) the logarithm of the exchange rates deflated by the IPCA $^{3}$ (Brazil' s Consumer Price Index).

In all cases the parameters were estimated by the maximum ikelihood criterion 4 . The optimization was repeated from 10 initial points chosen at random in a relevant region. An index of multiplicity of modes IMM was defined as the standard deviation of the Loglikelihood (LL) of the 10 optimization trials.

To test he predictive capacity of the models, the last 100 observations were taken away from the estimation sample. The lag of the VAR model is defined in monthly terms, but we wanted to use the entire daily measured sample. Our approach was to consider a lag of 21 days - the medium number of commercial days in a month - and to estimate the models as though the daily data were 21 replications of monthly data.

To validate the estimations, a simulation exercise was realized with the specifications 1 and 2 . In those cases, 100 samples where generated conditioned to the value of the estimator $(\hat{\psi})$ obtained with real data, and repeating the optimization exercise with 10 trials as already described. Thus, a sample of the distribution of the estimators of the parameters where obtained. In what follows, each specification is described with more details along with its corresponding results.

In all cases, the same model is estimated, namely equations (1) and(8), where the specifications are characterized by the definition of the vectors $\left(X_{t}, Y_{t}\right)$.

\subsection{Case A: The term structure of interest rates in Brazil}

This model relates the dynamics of the short rate $X$, the 1-day swap of the BM\&F, with the term structure $Y$ of swaps of other maturities. It is the simplest specification, for the stochastic process that has only 1 quantity - the 1-day rate

- and contains only 2 risk premium parameters, the constant one and the one proportional to level of the short rate. Figure 1 shows the trajectory of those rates,

\footnotetext{
${ }^{3}$ we supposed that the level of IPCA was Constant each day over a month.

${ }^{4}$ Using the fminsearch routine from mathlab 6.5.
} 
where the elevated correlation among them can be seen. In fact, we found that the first component of the canonic decomposition of the correlation matrix of those rates explains $95 \%$ of the total variability of the series.

The table A1 shows the value of the log-likelihood (LL) at the optimal point and the index of multiplicity of modes, which featured a positive value. After that, statistics relative to the simulation exercise are shown: The mean value of the $\mathrm{LL}$ conditioned to the true value of the parameters, and then conditioned to the optimal value in each estimation. The mean value of the IMM is shown too, and a measure of the variability of the $L L$ conditional to the estimated value of the parameters.

Tab A-1: Estimated and simulated log likelihood

\begin{tabular}{|c|c|c|c|c|c|}
\hline \multicolumn{2}{|l|}{ Estimation } & \multicolumn{4}{|l|}{ Simulation } \\
\hline LL & IMM & $\mathrm{M}(L L \mid \psi)$ & $M(L L \mid \hat{\psi})$ & $\mathrm{M}(\mathrm{IMM})$ & $\operatorname{SD}(L L \mid \hat{\psi})$ \\
\hline-2121. & 19.8 & -1604.2 & -1603.1 & & 9.1 \\
\hline
\end{tabular}

The results show that the LL has multiple modes, and that even so the adopted optimization algorithm obtains the minimum value, as can be seen in the comparison between the mean value of the LL conditioned to the true value of the parameters and to the estimated value. Table $A 2$ shows the estimated values of the parameters of the model and the corresponding estimated standard deviation. Moreover, it shows the simulated results, the value utilized in the generation of the samples, and the mean value of the $\hat{\psi}$, and the corresponding standard deviation. Finally, it shows the correlation between the estimators.

Tab A-2: Risk Premium and other Parameters

\begin{tabular}{|c|c|c|c|c|c|c|c|c|c|}
\hline & \multicolumn{2}{|c|}{ Estimation } & \multicolumn{7}{|c|}{ Simulation } \\
\hline & $\hat{\psi}$ & $\mathrm{SD}(\hat{\psi})$ & $\psi$ & $E(\hat{\psi})$ & $\operatorname{SD}(\hat{\psi})$ & 20 & $a$ & $\phi$ & V \\
\hline to & 0.90 & 0.01 & $0.9 \mathrm{~d}$ & 0.96 & 0.30 & 1.00 & $|-0.98|$ & -0.67 & -0.37 \\
\hline$a$ & -0.08 & 0.00 & -0.08 & -0.08 & 0.02 & -0.98 & 1.00 & 0.72 & 0.28 \\
\hline$\phi$ & 0.92 & 0.01 & 0.92 & 0.92 & 0.01 & -0.67 & 0.72 & 1.00 & 0.21 \\
\hline V & 0.02 & 0.00 & 0.01 & 0.01 & $0.0 d$ & -0.37 & 0.28 & 0.21 & \begin{tabular}{|l|}
1.00 \\
\end{tabular} \\
\hline
\end{tabular}

The results show that the parameters are measured with precision, and that the mean value of $\hat{\psi}$ is similar to the true value of the parameters, as well as the estimation of its standard deviation. This happens in spite of the estimated high correlation between the risk premiums. Table $\mathrm{A} 3$ presents the comparison among 
the values of the observed and the model predicted rates in the last period, as well as the mean value of this quantity predicted in the simulation exercise. It then shows the results corresponding to the parameters $\sigma$ relative to the error in the equations $x x$.

Tab A-3: Term in the final Period and $\sigma$

\begin{tabular}{|r|r|r|r|r|r|r|r|}
\hline$T$ & \multicolumn{4}{|l}{$Y(T,)}$. & \multicolumn{2}{l|}{$\sigma$} \\
\hline & $Y$ & $\hat{Y}$ & $\mathrm{M}(\hat{Y})$ & $\mathrm{SD}(\hat{Y})$ & $\hat{\sigma}$ & $\mathrm{M}(\hat{\sigma})$ & $\mathrm{SD}(\hat{\sigma})$ \\
\hline 1 & 0.19 & 0.19 & 0.2059 & 0.0033 & 0.01 & 0.0046 & 0 \\
\hline 2 & 0.19 & 0.20 & 0.208 & 0.0033 & 0.01 & 0.0085 & 0.0001 \\
\hline 3 & 0.19 & 0.20 & 0.2101 & 0.0033 & 0.01 & 0.0156 & 0.0001 \\
\hline 6 & 0.19 & 0.20 & 0.216 & 0.0033 & 0.02 & 0.0254 & 0.0005 \\
\hline 9 & 0.19 & 0.21 & 0.2213 & 0.0033 & 0.03 & 0.0239 & 0.0003 \\
\hline 12 & 0.19 & 0.22 & 0.2262 & 0.0033 & 0.03 & 0.0305 & 0.0002 \\
\hline 16 & 0.18 & 0.22 & 0.2346 & 0.0033 & 0.04 & 0.0386 & 0.0003 \\
\hline 24 & 0.17 & 0.23 & 0.241 & 0.0034 & 0.05 & 0.0491 & 0.0005 \\
\hline 36 & 0.17 & 0.24 & 0.2478 & 0.0034 & 0.06 & 0.0613 & 0.0008 \\
\hline
\end{tabular}

The results show that the term structure of these rates were not recuperated in the last period - 30 of may of 2005 - possibly because of the atypical characteristics of the term structure in Brazil caused by monetary policy. The results relative to the parameter $\sigma$ show that the estimator of this parameter was adequate in the simulation exercise.

Next, table A4 presents the predictive capacity of the model through the TheitU statistics that measure the ratio between the standard deviation of the error of the prediction and of the error of the random walk. The results show that the model has predictive capacity - T-U less than 1 for prediction up to 3 months. The simulation exercise shows that with simulated data, the model exhibits predictive capacity for all horizons, and that those statistics are measured with precision.

Tab A-4: Predictive capacity

\begin{tabular}{|l|ll|l|l|l|l|}
\hline$T$ & \multicolumn{4}{|l|}{$T-U(t \mid t)$} & \multicolumn{3}{|l|}{$T-U(t \mid t-1)$} \\
\hline & $M V$ & $M()$. & $D P()$. & $M V$ & $M()$. & $D P()$. \\
\hline 1.00 & 0.27 & 0.32 & 0.00 & 0.46 & 0.93 & 0.00 \\
\hline 2.00 & 0.57 & 0.48 & 0.01 & 0.35 & 0.87 & 0.01 \\
\hline 3.00 & 0.92 & 0.61 & 0.01 & 0.51 & 0.80 & 0.01 \\
\hline 6.00 & 2.24 & 0.67 & 0.01 & 1.73 & 0.76 & 0.01 \\
\hline
\end{tabular}




\begin{tabular}{|r|rr|r|r|r|r|}
\hline 9.00 & 3.49 & 0.67 & 0.01 & 3.00 & 0.76 & 0.01 \\
\hline 12.00 & 5.03 & 0.67 & 0.01 & 4.55 & 0.73 & 0.01 \\
\hline 18.00 & 7.28 & 0.69 & 0.00 & 6.87 & 0.73 & 0.01 \\
\hline 24.00 & 9.01 & 0.71 & 0.01 & 8.65 & 0.73 & 0.01 \\
\hline 36.00 & 10.58 & 0.71 & 0.01 & 10.31 & 0.73 & 0.01 \\
\hline
\end{tabular}

Figure 1 below shows the impulse response function of the interest rates of various maturities to the short rate shock. We see that the longer the maturity of the rate, the lower the effect of the shock.

Fig1: Impulse response functions and the trajectory of the rates in the period.
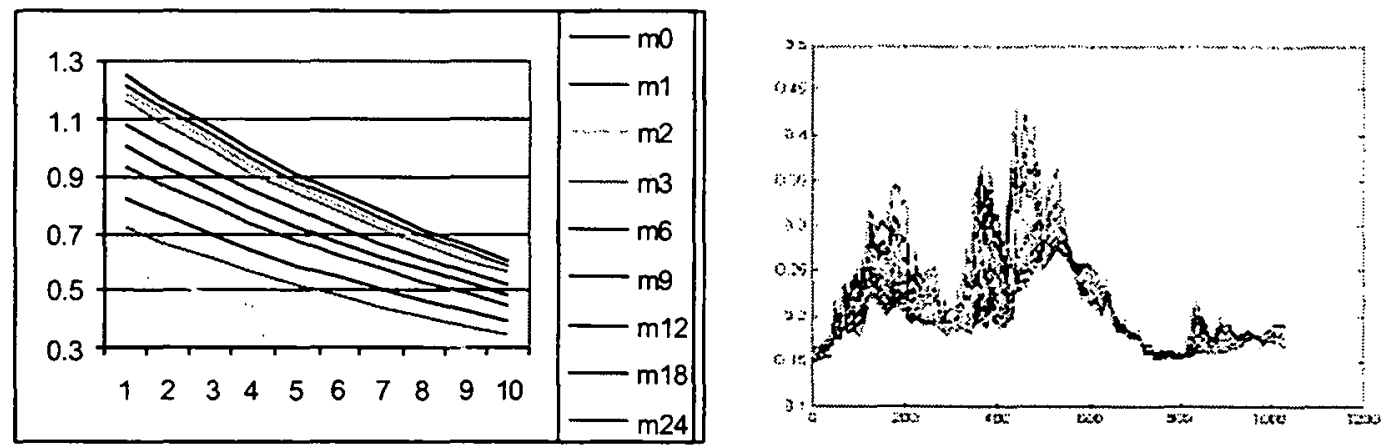

\subsection{Case B: Nominal exchange rate shock and term structure of interest rates in} Brazil

This specification extends the previous model including the exchange rate, which is a macro variable that is measured with daily frequency. With this specification we intend to analyze the interaction between the financial shocks over the interest rates and exchange rate shocks. Being measured in nominal terms, the latter variable captures aspects of the unbalances in the exchange market and in the domestic nominal shocks. The tables in the following are similar to the tables presented in the previous case, so we will comment only its results. In this case the state variables are $X=($ short rate, log of the exchange rate $R \$ / U S \$)$, the risk premiums have 6 components, 2 relative to the constant component, and 4 relative to components proportional to the state variables.

Tab B-1: Estimated and Simulated log likelihood

\begin{tabular}{|c|c|c|c|c|c|}
\hline \multicolumn{2}{|l|}{ Estimation } & \multicolumn{4}{|l|}{ Simulation } \\
\hline LL & IMM & $M(L L \mid \psi)$ & $M(L L \mid \hat{\psi})$ & $\mathrm{M}(\mathrm{IMM})$ & $\operatorname{SD}(L L \mid \hat{\psi})$ \\
\hline-2149.2 & 8.3 & -1179.3 & -1170.0 & 19.1 & 24.6 \\
\hline
\end{tabular}


The results of the table B1 show that the LL displays multiple modes and that the optimization algorithm found the global optimum. The table B2 shows that the risk premiums are estimated with precision according to the calculation carried out with the Hessian of the LL. The simulation exercise shows conflicting results. The mean value of the estimators $\hat{\psi}$ disagrees with the values with which the samples were generated, a fact confirmed by the value of the standard deviation of $\hat{\psi}$. These results characterize an identification problem in those models that suggests the necessity of imposing restrictions over those parameters.

Tab B-2: Risk Premium

\begin{tabular}{|c|c|c|c|c|c|c|c|c|c|c|c|}
\hline & \multicolumn{2}{|c|}{ Estimation } & \multicolumn{9}{|c|}{ Simulation } \\
\hline & $\hat{\psi}$ & D.P & $\psi$ & $M(\hat{\psi})$ & $\mathrm{DP}(\hat{\psi})$ & $20(c)$ & ho(j) & $\lambda(c, c)$ & $2(c, j)$ & $\lambda(j, c)$ & $\mu(j, j)$ \\
\hline $\mathrm{hO}(\mathrm{c})$ & 3.45 & 0.02 & 3.45 & 1.10 & 2.51 & 1.00 & 0.02 & -0.27 & -0.12 & -0.17 & 0.08 \\
\hline $20(j)$ & -0.28 & 0.01 & -0.28 & -0.71 & 1.83 & 0.02 & 1.00 & 0.50 & 0.10 & -0.79 & 0.21 \\
\hline$h(c, c)$ & -0.10 & 0.00 & -0.10 & 0.12 & 0.47 & -0.27 & 0.50 & 1.00 & 0.35 & -0.53 & 0.33 \\
\hline$\lambda(c, j)$ & -10.20 & 0.00 & -0.20 & -0.16 & 0.81 & -0.12 & 0.10 & 0.35 & 1.00 & 0.14 & -0.29 \\
\hline$h(j, c)$ & 0.01 & 0.00 & 0.09 & 0.12 & 0.07 & -0.17 & -0.79 & -0.53 & 0.14 & 1.00 & -0.75 \\
\hline$a(j, j)$ & -10.08 & 0.00 & -0.08 & -0.07 & 0.09 & 0.08 & 0.21 & 0.33 & -0.29 & -0.75 & $1.0 \mathrm{~d}$ \\
\hline
\end{tabular}

The Table B3 presents the rates of the last period and the parameter $\sigma$ relative to the error in the equation of the rates of various maturities. The results show that, similarly to the previous case, the model could not recover, the term structure in the last period, but the parameter $\sigma$ looks adequately measured.

Tab B-3: Term in the final period and $\sigma$

\begin{tabular}{|l|l|l|r|r|r|r|r|}
\hline Mat. & \multicolumn{1}{|l|}{$Y(\mathrm{~T},)}$. & \multicolumn{1}{l|}{$\sigma$} \\
\hline & $Y$ & $\hat{Y}$ & $\mathrm{M}(\hat{Y})$ & $\mathrm{DP}(\hat{Y})$ & $\hat{\sigma}$ & $\mathrm{M}(\hat{\sigma})$ & $\mathrm{SD}(\hat{\sigma})$ \\
\hline 1 & 0.19 & 0.19 & 0.19 & 0.00 & 0.01 & 0.02 & 0.00 \\
\hline 2 & 0.19 & 0.19 & 0.17 & 0.00 & 0.01 & 0.02 & 0.00 \\
\hline 3 & 0.19 & 0.19 & 0.16 & 0.00 & 0.01 & 0.03 & 0.00 \\
\hline 6 & 0.19 & 0.20 & 0.10 & 0.00 & 0.02 & 0.04 & 0.00 \\
\hline 9 & 0.19 & 0.20 & 0.05 & 0.00 & 0.03 & 0.05 & 0.00 \\
\hline 12 & 0.19 & 0.21 & 0.01 & 0.00 & 0.03 & 0.05 & 0.00 \\
\hline 18 & 0.18 & 0.22 & -0.08 & 0.00 & 0.04 & 0.07 & 0.00 \\
\hline 24 & 0.17 & 0.22 & -0.14 & 0.00 & 0.05 & 0.10 & 0.00 \\
\hline 36 & 0.17 & 0.24 & -0.23 & 0.00 & 0.06 & 0.12 & 0.00 \\
\hline
\end{tabular}


Table B4 shows that the introduction of the macro variable improves the predictive capacity of the model. The predictive capacity rose up to a horizon of 6 months.

Tab B-4: Capacity of Prediction

\begin{tabular}{|c|c|c|c|c|c|c|}
\hline Mat & \multicolumn{3}{|c|}{ Theil-U(t|t) } & \multicolumn{3}{|c|}{ Their $U(t \mid t-1)$} \\
\hline & MV & $M()$. & $\operatorname{SD}()$. & MV & $M()$. & $\mathrm{SD}()$. \\
\hline 1 & 0.09 & 0.62 & 0.01 & 0.58 & 0.80 & 0.01 \\
\hline 2 & 0.18 & 0.66 & 0.01 & 0.53 & 0.78 & 0.01 \\
\hline 3 & 0.33 & 0.68 & 0.01 & 0.46 & 0.74 & 0.01 \\
\hline 6 & 1.14 & 0.71 & 0.01 & 0.84 & 0.74 & 0.01 \\
\hline 9 & 2.05 & 0.71 & 0.01 & 1.76 & 0.73 & 0.01 \\
\hline 12 & 3.32 & 0.71 & 0.01 & 3.07 & 0.73 & 0.00 \\
\hline 18 & 5.47 & 0.71 & 0.01 & 5.36 & 0.73 & 0.01 \\
\hline 24 & 7.30 & 0.72 & 0.01 & 7.31 & 0.73 & 0.01 \\
\hline 36 & 9.16 & 0.73 & 0.01 & 9.39 & 0.73 & 0.01 \\
\hline
\end{tabular}

The figures in the following show the dynamic characteristics of the effect of the shock over the interest rates and over the exchange rate. The structural shocks were calculated supposing that contemporaneously the exchange rate variation is exogenous, and that the variation of the interest rate is conditional to the exchange rate shock. Our results indicated the following:

1. The figure 2 shows that the exchange rate goes up with a interest rate shock and that the exchange rate shock has a lower effect over the interest rates;

2. The impulse response function (IRF) in figure 3 shows that the effect of the exchange rate shocks $(C)$ over the interest rates reduces over time, but the variance decomposition function (VDF) explains the greatest part of the variation of the interest rates in the various maturities, and in particular the effects grows with the maturities. The greater the maturity, the greater the proportion of the variance that is due to the exchange rate shock;

3. The results relative to the interest rate shocks $(\mathrm{J})$ are similar; the effect of the shock diminishes over time. 
Fig2:IRF of the exchange rate and the short rate to macro shocks
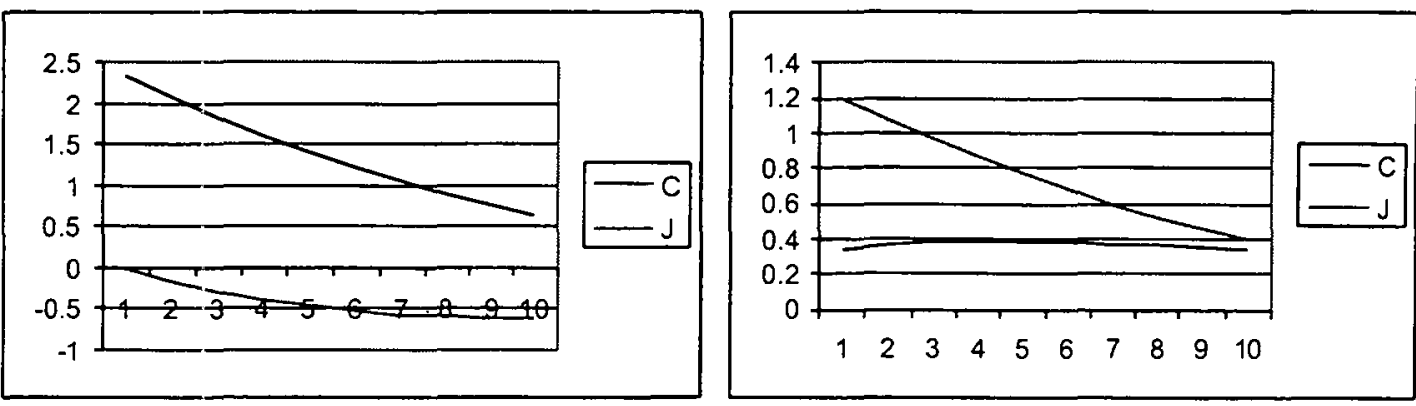

Fig3:IRF and VDF of the exchange rate shock, various maturities.
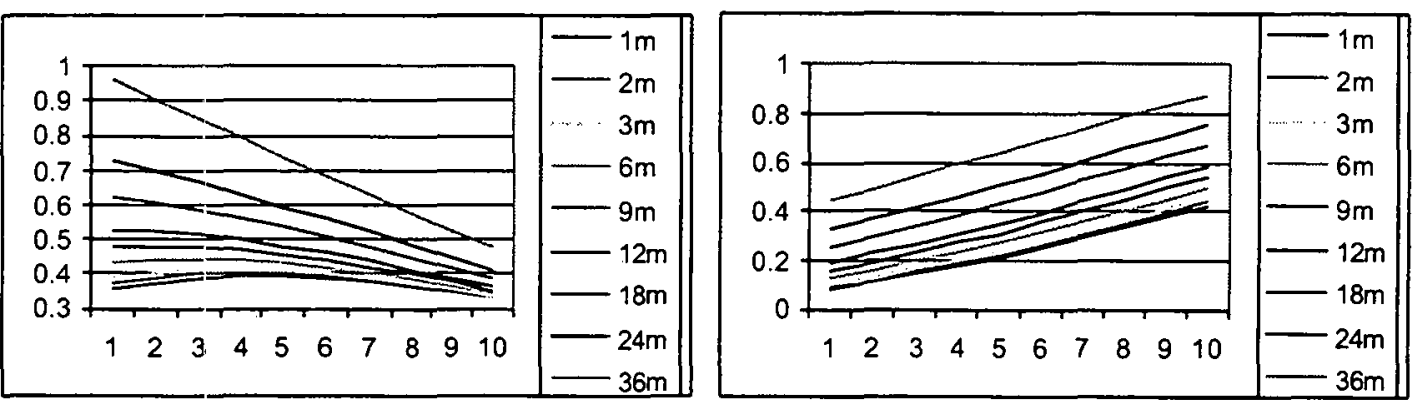

Fig4: IRF, VDF of the interest rate shocks, various maturities
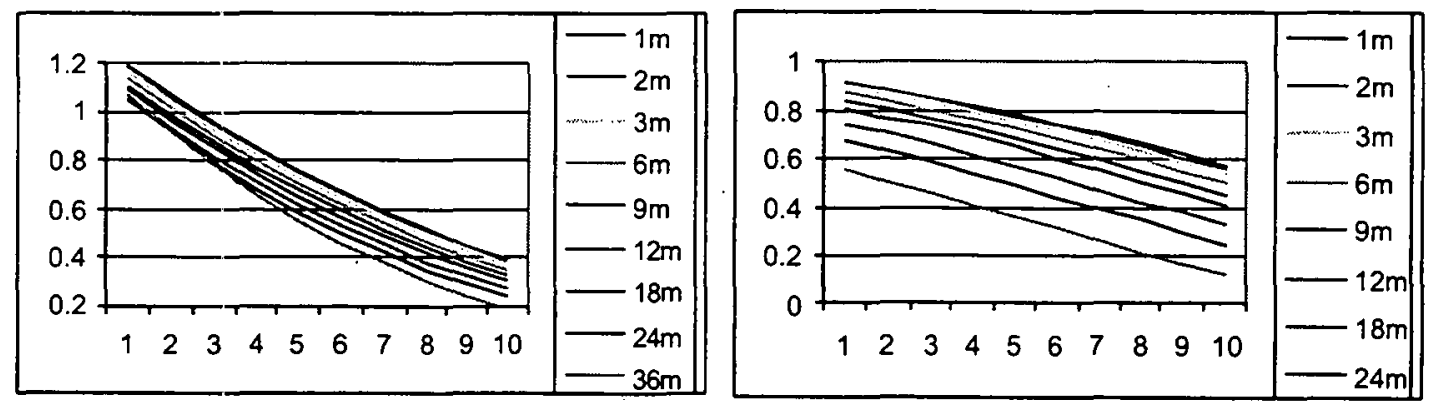

\subsection{Case C: Term structure of interest rates in the USA}

This model relates the dynamics of the interest rates $(X)$ to the term structure $(Y)$ through the risk premiums. The specification is identical to case $A$, but utilized to analyze the US term structure, which has Treasury bonds of much longer maturity, 20 years in contrast to 3 in Brazil. Figure 5 shows the trajectory of those rates. They display less correlation than in Brazil. The first component explains only $85 \%$ of the total variation, which suggests a limitation of having only 1 factor. 
The estimated LL was (-3866) and the IMM was nil, indicating that in this case multiple modes case were not found. The table $\mathrm{C} 1$ shows that the parameters were estimated with precision.

Tab C-1:Risk Premium

\begin{tabular}{|l|l|l|l|l|l|}
\hline$\hat{\psi}$ & \multicolumn{1}{l|}{$\lambda$} & \multicolumn{1}{l|}{$\lambda$} & \multicolumn{1}{l|}{$\phi$} & \multicolumn{1}{l|}{} \\
\hline $\mathrm{SD}$ & 0.0932 & -0.2298 & 0.7533 & 0.0031 & 0.0018 \\
\hline
\end{tabular}

Table C2 shows that the term structure in the last period - may of 2005 - is predicted similarly to the observed, but that the predictive capacity of the model is inferior to the random walk except for the maturity of 5 years. This is further evidence of the limitations of a model that has only one factor to explain the movements of the term structure. To evaluate if the monthly specification with lags of 21 days could be the source of the low predictive capacity, the model was estimated in a daily specification, and that type of result was maintained. Therefore, the inclusion of information contained in a second latent factor could be important to strengthen the predictive capacity in a case were one has bnger maturities.

Tab C-2: Other parameters and predictive capacity

\begin{tabular}{|l|r|r|l|r|r|}
\hline Mat & $Y(T,)$. & $E(Y(T,))$. & $\sigma$ & $T-U(t \mid t)$ & $T-U(t, t-1)$ \\
\hline 1 & 0.03 & 0.03 & 0.00 & 1.63 & 3.47 \\
\hline 2 & 0.03 & 0.04 & 0.00 & 1.37 & 2.76 \\
\hline 5 & 0.04 & 0.04 & 0.01 & 0.60 & 0.86 \\
\hline 10 & 0.05 & 0.04 & 0.00 & 2.15 & 1.48 \\
\hline 20 & 0.05 & 0.05 & 0.00 & 3.22 & 2.81 \\
\hline
\end{tabular}

The figure 5 shows that, according to the model, in USA the monetary shock is temporary and is lower for the longer rates as expected. 
Fig5: IRF and Trajectory of American Rates of a number of maturities
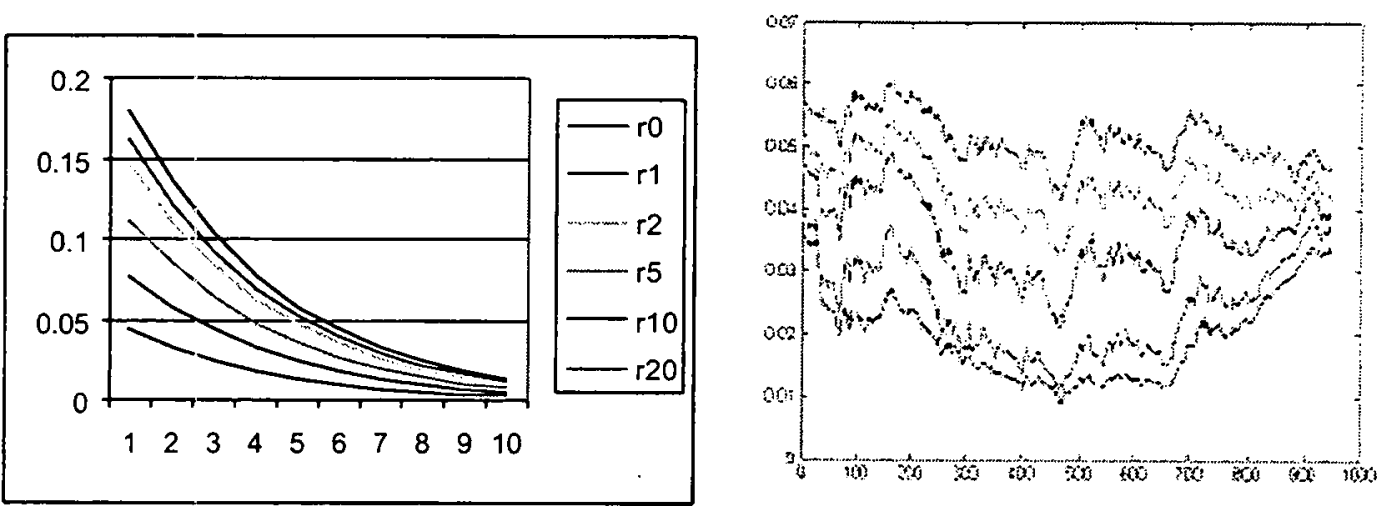

\subsection{Case D: Sovereign Spread and shocks over its determinants}

This is the lasit case, and one of the objectives of this article is to utilize AP's framework in the credit risk setting. This model relates the dynamics and the risk premiums of the Brazilian sovereign spreads to the dynamics and the risk premiums of American rates, and includes the effect of a measure of the vulnerability of the Brazilian public debt. Unfortunately this version can be subject to some criticisms beforehand, due to empirical limitations.

Up to the knowledge of the authors, there do not exist available measures of the spread or of the interest rates of the external bonds issued by the Republic of Brazil corrected to constant maturity. The obligations are issued with coupon payments. For this reason, we utilized a methodology described briefly in the appendix to calculate the Zero-Coupon curve. The prices of the bonds were obtained from the Morgan Market, which do not dispose of bonds with short maturities already matured. This turned the estimation of the spreads especially precarious in the beginning of the sample. Figure 6 in the following shows the rates of return of selected bonds and the constant maturity spread rates. 
Fig 6: Constant maturity spreads and rates of the bonds.
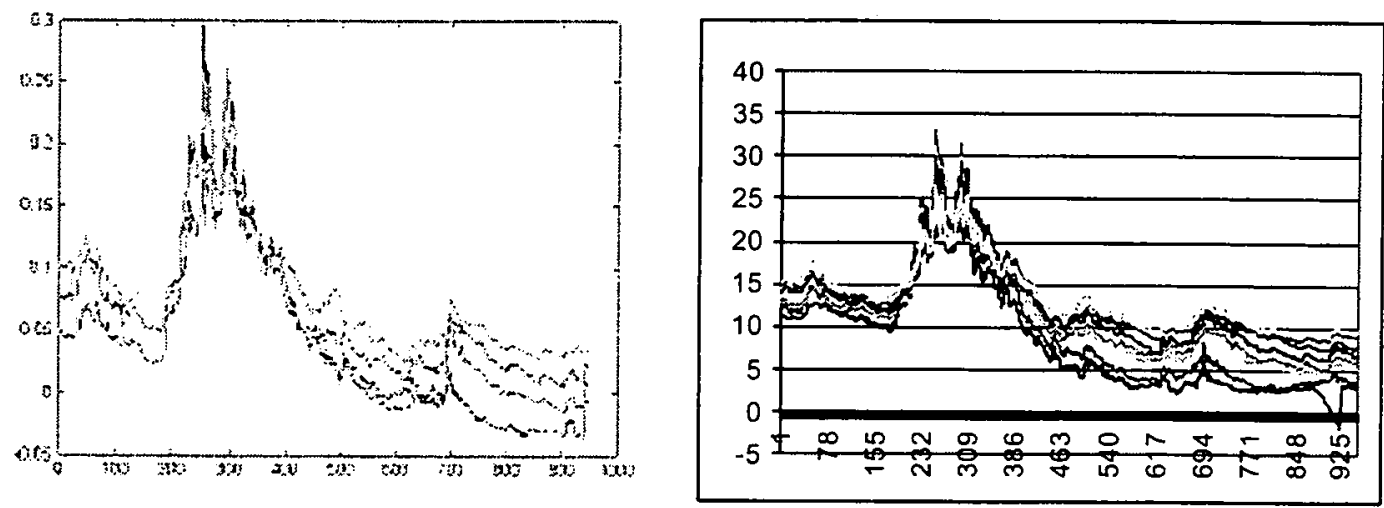

The spreads of those bonds are negotiated outside of Brazil and are related to the risk of default. Thus, it is convenient to incorporate a measure of vulnerability of the indebtedness of the country or of the Brazilian state. Since in most part of the sample period - 2001/2005 - the majority of the Brazilian public debt was indexed to a foreign currency, as bonds issued abroad or as bonds issued in the domestic market but indexed to the exchange rate, the exchange rate is a synthetic and diary exposition to risk. Unfortunately for our objectives, but fortunately for our country, the government adopted the policy of reducing drastically the debt indexed to the US\$, which turned this measure improper towards the final of the sample.

In this model, the state variables $X$ are the short rate $(r)$ in USA, the log of the real exchange rate (c), and the short credit spread of Brazil (s) - that due to lack of information was the spread relative to 1 year. The model was estimated conditional to the risk premium and the dynamic properties of the rates in USA estimated in the previous case.

The stochastic process of the state variables and the risk premium are:

$$
X_{t}=\left[\begin{array}{l}
r \\
c \\
s
\end{array}\right]=\left[\begin{array}{ccc}
\phi_{u} & 0 & 0 \\
\phi_{c u} & \phi_{c c} & \phi_{c s} \\
\phi_{s u} & \phi_{s c} & \phi_{s s}
\end{array}\right] X_{t-1}+e_{t} \Delta_{t}=\left[\begin{array}{l}
\lambda_{u} \\
\lambda_{c} \\
\lambda_{s}
\end{array}\right]+\left[\begin{array}{ccc}
\lambda_{u} & 0 & 0 \\
\lambda_{c u} & \lambda_{c c} & \lambda_{c s} \\
\lambda_{s u} & \lambda_{s c} & \lambda_{s s}
\end{array}\right] X_{t}
$$

The estimated model found $L L=-2015$ and $I M M=272$, which indicates that the algorithm found multiple modes, and that there are expressive differences among them. The estimators of the risk premium are presented in table D1, which shows 
that for some of the estimators one does not reject the hypothesis that they are null, suggesting, as in case $B$, the existence of identification problems.

Tab D-1 : Risk Premium

\begin{tabular}{|c|c|c|c|c|c|c|c|c|}
\hline & $\lambda 0(c)$ & $\lambda O(s)$ & $\lambda(c, r)$ & $\lambda(c, c)$ & $\lambda(\mathrm{c}, \mathrm{s})$ & $\lambda(s, r)$ & $\lambda(\mathrm{s}, \mathrm{c})$ & $\lambda(s, s)$ \\
\hline$\hat{\psi}$ & 0.93 & 1.51 & 0.48 & 1.86 & -0.70 & -0.04 & 0.07 & 0.73 \\
\hline S.D. & 0.107 & 0.068 & 0.808 & 0.001 & 0.003 & 0.103 & 0.001 & 0.004 \\
\hline
\end{tabular}

This model does not exhibit predictive capacity. Also, the term structure is not adequately predicted.

\section{Tab D-2 : Other statistics}

\begin{tabular}{rrrrrr} 
Mat & \multicolumn{1}{c}{$T-U(t \mid t)}$. & \multicolumn{1}{c}{$T-U(t \mid t-1)$} & $\sigma$ & $E(Y(T,))$. & $\dot{Y}(T,)$. \\
6 & 7.11 & 6.93 & 0.07 & 0.06 & 0.01 \\
10 & 6.24 & 6.09 & 0.05 & 0.06 & 0.02 \\
20 & 11.56 & 11.36 & 0.04 & 0.07 & 0.03
\end{tabular}

The structural shocks of the model were identified supposing that the shocks of interest rates in USA are exogenous for the Brazilian economy, and that the shocks in the vulnerability - the exchange rate - are determined by the external shocks and determines the unexpected alterations of the spread. This order defines how was defined the Cholesky decomposition used to identifie these structural schoks in the Var model. Those shocks were denominated as external (R), vulnerability (C), and spread (S).

The figures below show the dynamic properties of this model:

- The effects of the shocks over the spread are: The increase of the vulnerability has a short and transitory positive effect; the rise of the perception of risk has a positive effect for a longer period; and, finally, the external shock has an increasing effect over the spread.

- Only the variance decomposition of the effect of the spread of maturity 20 is shown, because the other maturities are similar. In the tenth month after the shock, the effect of the shock explains $40 \%$ of the variation, whereas the vulnerability shock has no effect anymore and the spread shock explains the complement. 
Fig7: IRF of the Real Exchange Rate and of the Spreads to Shocks
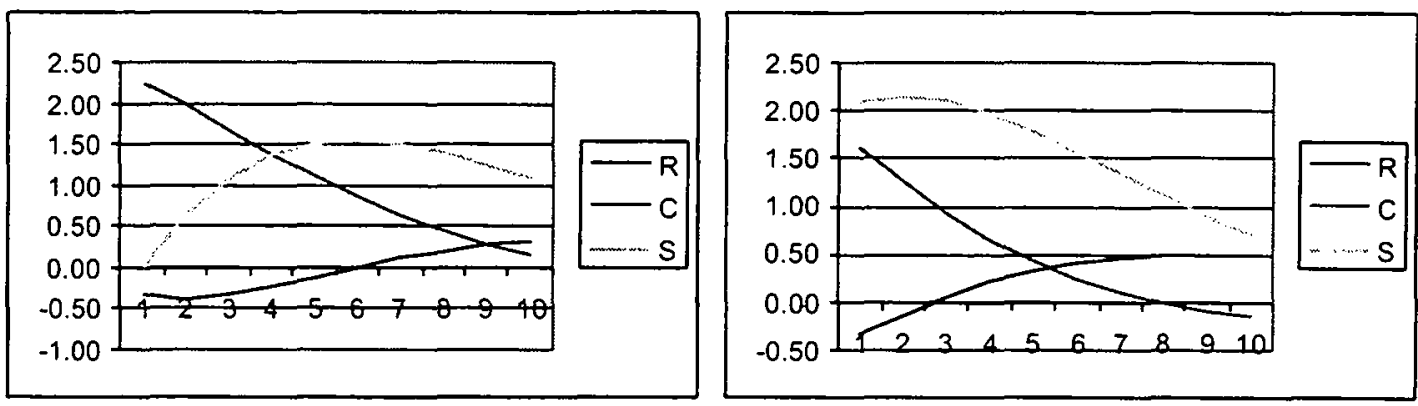

Fig9:IRF and VDF : External Shock (US short rate shock)
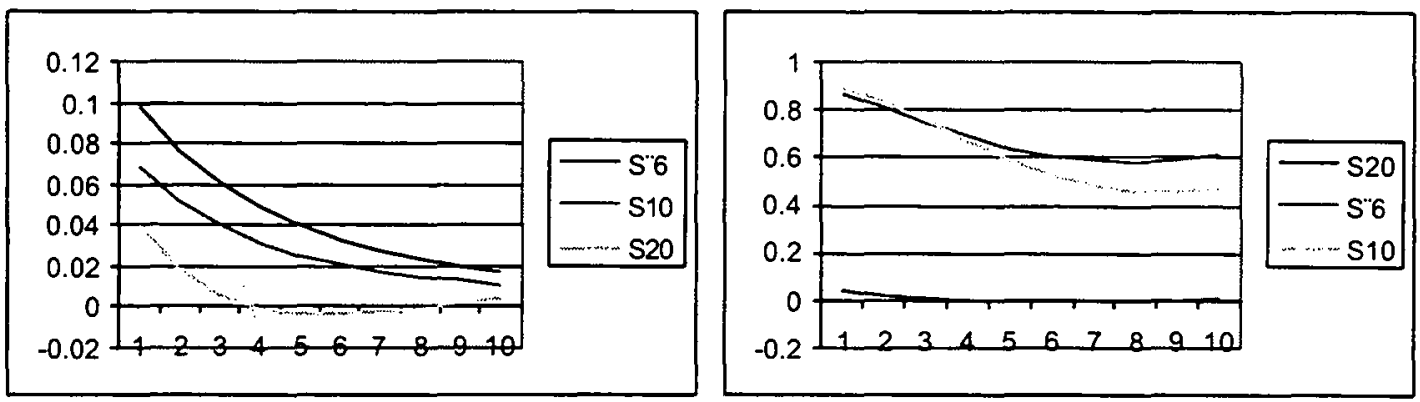

Fig10:IRF and VDF : Vulnerability shock (real exchange rate)
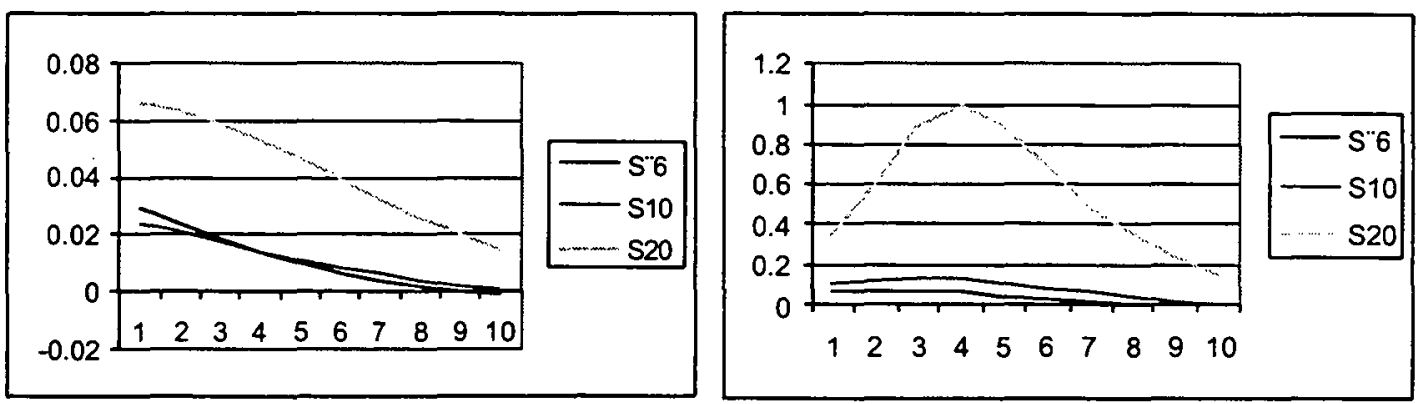

Fig11:IRF and VDF : Spread shocks
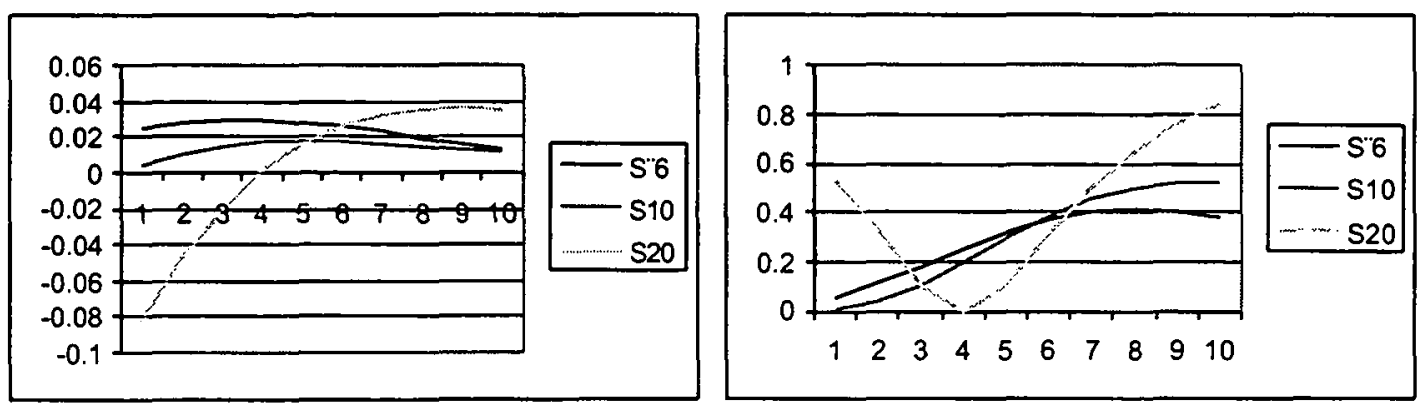


\section{Conclusion}

This exercise showed the variety of questions that a simplified version of the AP's model is able to treat, the effect of this simplification over the predictive capacity of the longer rates, and the difficulties of the estimation of risk premiums even in this simplified setting. Those difficulties suggest the existence of limitations concerning the possibility of estimating all the parameters of risk premium, and therefore the necessity of investigating how to introduce restrictions over the specifications of the risk premium in order to make them identifiable to the models with more than one factor.

We proposed a simplification and a method of estimation that to our point of view greatly reduced identification problems, but we recognize that using the short rate as the only latent variable constrained the predictive and explanatory capabilities of our model.

On the other hand, we believe that the addition of a new state variable, namely the short spread, alleviated that problem when studying the Brazilian sovereign curve. More importantly, a major objective of our line of research is trying to find the determinants of the credit spreads, since the understanding of the credit spread is of utmost importance in the study of emerging markets term structure, and a model with more latent variables would make the estimation process too complex.

Furthermore, our proposal is a multidimensional affine model for the term structure of interest rates that is as easy to estimate as common empirical procedures.

In view of empirical difficulties due to lack of data, our results are still preliminary, but we document that exchange rate and the American short rate explain a significant portion of the Brazilian term structure. Moreover, it must be stressed that only difficulties with lack of data prevent us of studying the relation of more macroeconomic variables with the interest rates and credit spreads.

Our results up to this point shows interesting interactions between financial and macro variables. For instance, in the model $B$ the effect of exchange rate shocks explains a major part of the variation of interest rates, and the effect grows with 
longer maturities, and in the model $D$ the external shock has an increasing effect over the spread.

Future work will also contemplate the correlation effects among the emerging countries. That is, we would like to know for instance how Brazilian credit spread is affected or affects Russian or Argentinean credit spread. This kind of study can be more easily implemented in the present setting than in continuous time models. Moreover, the addition of correlation will enable us to have 3 latent variables as state variables, namely, the risk-free short rate, and the Brazilian and, for instance, the Russian short spreads, and studies by Litterman and Scheinkman and Dai and Singleton have indicated that exactly 3 state variables are need to study the term structure.

Finally, we list tasks to be immediately executed:

- To Obtain a more accurate description of the term structure of the spreads, in particular a more adequate measure of the short rate;

- To Search for another measure of the vulnerability of the indebtedness, eventually measured monthly or trimester;

- To Extend the model to consider more than one quantitative factor approximating AP's specification; 


\section{References:}

1. A no-arbitrage vector autoregression of term structure dynamics with macroeconomic and latent variables, 2003, Ang A. Piazzesi, M. Journal of Monetary Economics 50, 745-787.

2. No-Arbitrage Taylor Rules, 2005, Ang, Andrew; Dong, Sen and Piazzesi, Monika. Working paper, University of Chicago.

3. Modeling Bond Yields in Finance and Macroeconomics, Francis X. Diebold, Monika Piazzesi, and Glenn D. Rudebusch, American Economic Review P\&P (2005)

4. Duffie, D., Kan, R., 1996. A Yield-Factor Model of Interest Rates, Mathematical Finance, 6, 379-406.

5. Harrison, J. M., Kreps, D. M., 1979. Martingales and Arbitrage in Multiperiod Securities Markets, Journal of Economic Theory, 2, 381-408.

6. Chen, R. R., Scott, L., 1993. Maximum Likelihood Estimation for a Multi-factor Equilibrium Model of the Term Structure of Interest Rates, Journal of Fixed Income, 3, 14-31.

7. Duffie, D., L.. Pedersen, and K. Singleton (2000). Modeling Sovereign Yield Spreads: A Case Study of Russian Debt, Journal of Finance 58, 119-159.

8. Duffie, D. and K. Singleton (1999). Modeling Term Structures of Defaultable Bonds, Review of Financial Studies 12, 687-720.

9. Litterman,R, Scheinkman, J_(1991) Common factors affecting bond returns, Journal Fixed Income, 1, 51-61

10. Dai, Q., Singleton, K. (2000),Specification Analysis of term structure of interest rates, Journal of Finance 55, 1943-78. 
Appendix : A1 - Constant Maturity Interested Rate Calculation

The price of bond $i$ with coupon $(x)$, maturity $(T)$, yield to maturity $(j)$ is:

$\mathrm{P}(\mathrm{t}, \mathrm{i})=(1+\mathrm{j}(\mathrm{i}))^{\top(i)-\mathrm{t}}+\sum_{k=t}^{T(i)} \frac{x(i)}{(1+j(i))^{k-t}}$

The same price can be calculated using the term structure $r(k)$

$\mathrm{P}(\mathrm{t}, \mathrm{i})=(1+\mathrm{r}(\mathrm{T}(\mathrm{i})))^{-\mathrm{T}(\mathrm{i})-\mathrm{t}}+\sum_{k=t}^{T(i)} \frac{x(i)}{(1+r(k))^{k-t}}$

Supposing bonds are ordered by the maturities $T(1)<T(2)<$..

For $\mathrm{k}=1: \mathrm{r}(\mathrm{i})=\mathrm{j}(1) \forall \mathrm{i}<=\mathrm{T}(1)$

$\mathrm{P}(\mathrm{t}, \mathrm{i})=\sum_{k=t}^{T(i-1)} \frac{x(i)}{(1+r(k))^{k-t}}+(1+\mathrm{r})^{T} \mathrm{~T}(\mathrm{i})-\mathrm{t}+\sum_{k=T(i-1)+1}^{T(i)} \frac{x(i)}{(1+r)^{k-t}}$

For $T(i-1)<k<=T(i), r(k)=r_{-}(i)$

$\mathrm{P}(\mathrm{t}, \mathrm{i})=\sum_{k=f l o o r(2 t)+1}^{2 T(i-1)} \frac{x(i) / 2}{(1+r(k))^{k / 2-t}}+(1+\mathrm{r})-(T(\mathrm{~T})-\mathrm{t})+\sum_{k=2 T(i-1)+1}^{2 T(i)} \frac{x(i) / 2}{(1+r)^{k / 2-t}}$, or

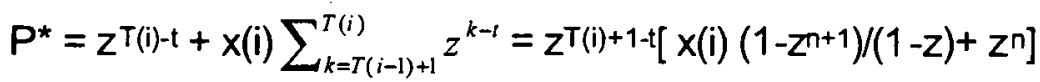

where

$\mathrm{P}^{\star}=\mathrm{P}(\mathrm{t}, \mathrm{i})-\sum_{k=t}^{T(i-1)} \frac{x(i)}{(1+r(k))^{k-t}}$

$z=(1+r)^{-1}$

the term rate for the interval $T(i), T(i+1)$ is given by the maximum real positive root of $z^{\top(i)+1-t}(x(i)+1)-z^{T(i)-t}-z^{T(i-1)+1-t} x(i)-P^{\star}(z-1)=0$

A2. Bonds used to calculated the spread : Brazilian Sovereign Bonds

\begin{tabular}{|l|l|}
\hline BR Republic $95 / 8 \%$ due 05 Yld To Mat & BR Republic $77 / 8 \%$ due 15 Yld To Mat \\
\hline BR Republic $101 / 4 \%$ due 06 Yld To Mat & BR Repùblic $11 \%$ due 17 ITL YId To Mat \\
\hline BR Republic 11 1/4\% due 07 Yld To Mat & BR Republic $87 / 8 \%$ due 19 Yld To Mat \\
\hline BR Republic $10 \%$ due 07 GBP Yld To Mat & BR Republic $123 / 4 \%$ due 20 Yld To Mat \\
\hline BR Republic $93 / 8 \%$ due 08 Yld To Mat & BR Republic $87 / 8 \%$ due 24 Yld To Mat \\
\hline BR Republic $141 / 2 \%$ due 09 Yld To Mat & BR Republic $87 / 8 \%$ due 24 - B Yld To Mat \\
\hline BR Republic $91 / 4 \%$ due 10 Yld To Mat & BR Republic $83 / 4 \%$ due 25 Yld To Mat \\
\hline BR Republic $12 \%$ due 10 Yld To Mat & BR Republic $101 / 8 \%$ due 27 Yld To Mat \\
\hline BR Republic $10 \%$ due 11 Yld To Mat & BR Republic $121 / 4 \%$ due 30 Yld To Mat \\
\hline BR Republic $11 \%$ due 12 Yld To Mat & BR Republic $81 / 4 \%$ due 34 Yld To Mat \\
\hline BR Republic $101 / 4 \%$ due 13 Yld To Mat & BR Republic $11 \%$ due 40 Yld To Mat \\
\hline BR Republic $101 / 2 \%$ due 14 Yld To Mat & \\
\hline
\end{tabular}




\section{FUNDAÇÃO GETULIO VARGAS BIBLIOTECA}

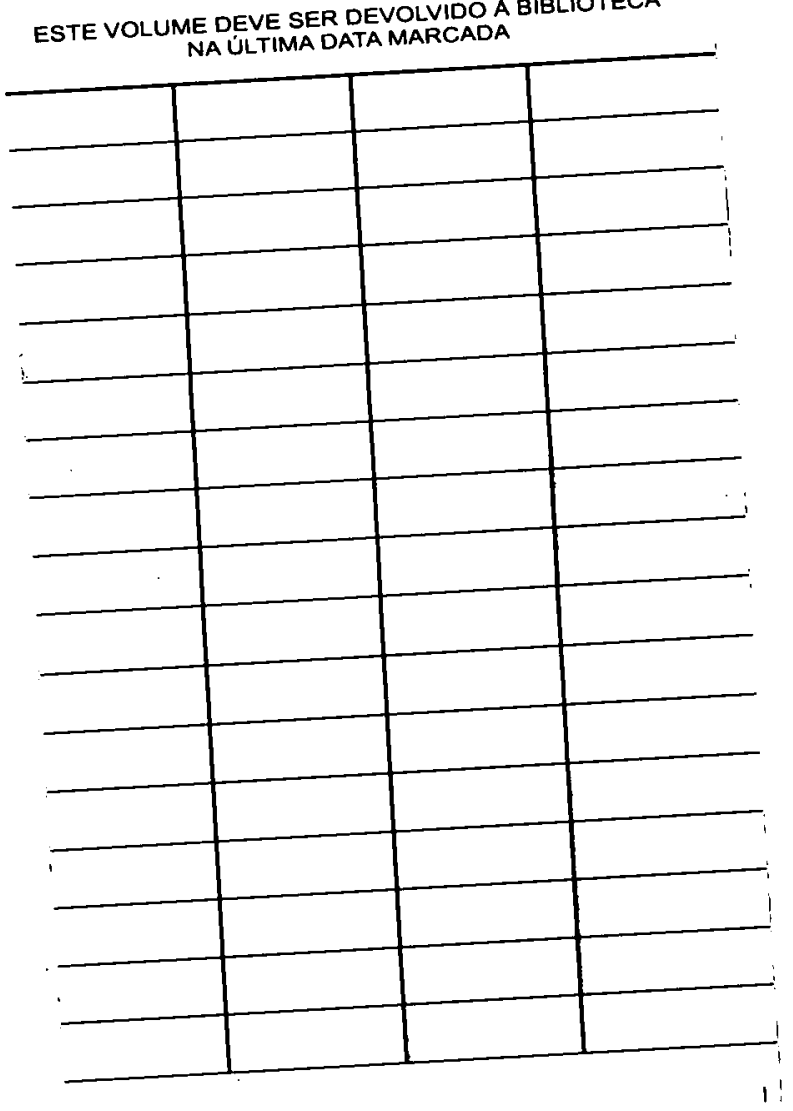

98606

BIBLIOTECA MARIO HENRIQUE SIMONSEN FUNDAÇAOO GETÚLIO VARGAS

370833

$5 / 912005$ 